\title{
LA EXTINCIÓN DE LA RELACIÓN LABORAL DE LAS TRABAJADORAS EMBARAZADAS DURANTE EL PERÍODO DE PRUEBA TRAS EL REAL DECRETO-LEY 6/2019, DE 1 DE MARZO
}

\author{
Xavier Solà i Monells \\ Profesor Titular de Derecho del Trabajo y de la Seguridad Social de la Universidad \\ Autónoma de Barcelona
}

\begin{abstract}
La aparición del Real Decreto-ley 6/2019 supone un importante paso adelante en la protección de las trabajadoras embarazadas frente a la extinción contractual durante el período de prueba, que hasta ese momento se había canalizado exclusivamente a través de la vía ordinaria de tutela de derechos fundamentales. El actual párrafo $2^{\circ}$ del artículo 14.2 del TRLET extiende a esa tipología extintiva la nulidad objetiva y automática que dos décadas atrás se introdujo para los despidos disciplinario y objetivo, generando una presunción que solo puede romperse acreditando la falta de aptitud y/o adecuación de la trabajadora embarazada. No obstante, la nueva regulación también presenta algunas deficiencias, porque genera diversos interrogantes, tanto en relación con el colectivo beneficiario de la garantía como a su alcance objetivo, y se olvida de transponer la obligación de notificación escrita y motivada de la decisión extintiva establecida en el artículo 10.2 de la Directiva 92/85/CEE.
\end{abstract}

The appearance of Royal Decree-Law 6/2019 supposes an important step forward in the protection of pregnant workers against contractual termination during the probationary period, which up to that time had been channelled exclusively through the ordinary route of protection of fundamental rights. The current $2^{\text {nd }}$ paragraph of article 14.2 of the TRLET extends to this extinctive typology the objective and automatic nullity that was introduced two decades ago for disciplinary and objective dismissals, generating a presumption that can only be broken by determining the lack of aptitude and/or adequacy of the pregnant worker. However, the new regulation also presents certain deficiencies because it raises a number of questions, both in relation to the collective benefiting from the guarantee and also to its objective range of effect. It also forgets to transpose the obligation of a written notification prompted by the established terminating decision in article 10.2 of Directive 92/85/CEE.

Title: The termination of the employment relationship during the probationary period of pregnant workers following the Royal Decree-Law 6/2019 of March $1^{\text {st }}$ 
Palabras clave: Trabajadora embarazada, período de prueba, discriminación, extinción contractual

Keywords: Pregnant worker, probationary period, discrimination, contractual termination

IUSLabor 1/2020, ISSN 1699-2938, p. 13-38.

DOI. 10.31009/IUSLabor.2020.i01.01

Fecha envío: 17.12.2019 | Fecha aceptación: 25.2.2020

\section{Sumario}

1. Planteamiento

2. La solución tradicional: la tutela basada en la presunción por indicios de discriminación

3. Una evolución fallida: la STS de 18 de abril de 2011 (recurso 2893/2010) y la STC 173/2013, de 10 de octubre

4. La corrección normativa a través del RDL 6/2019

4.1. Primera aproximación: la extensión al período de prueba de la garantía de nulidad objetiva y automática

4.2. El ámbito subjetivo de la garantía: identificación del colectivo beneficiario

4.3. El alcance objetivo de la garantía: la presunción "iuris tantum" de nulidad

4.4. La eventual incidencia sobre la mecánica extintiva: ¿obligación de comunicación escrita con especificación causal?

4.5. Las consecuencias de la nulidad

5. Reflexiones finales

6. Bibliografía 


\section{Planteamiento}

"El riesgo de pérdida del empleo como consecuencia de la maternidad de las mujeres trabajadoras constituye probablemente el problema más importante -junto con la desigualdad retributiva- con el que se enfrenta la efectividad del principio de no discriminación por razón de sexo en el ámbito de las relaciones laborales". Esta contundente afirmación, extraída del FJ $8^{\circ}$ de la STC 92/2008, de 21 de julio, denuncia una problemática más que conocida y acreditada a través de diversos estudios ${ }^{1}$, que el ordenamiento jurídico debe afrontar con intervenciones específicas.

En el ámbito del despido éstas se llevaron a cabo a través de la Ley 39/1999, de 5 de noviembre, para promover la conciliación de la vida familiar y laboral de las personas trabajadoras (en adelante Ley 39/1999), que introdujo en los artículos 54.3 y 55.5 del Texto Refundido de la Ley del Estatuto de los Trabajadores, aprobado mediante Real Decreto Legislativo 2/2015, de 23 de octubre (en adelante TRLET), un sistema que tanto la jurisprudencia como la doctrina han considerado una garantía reforzada en la protección de las trabajadoras embarazadas y que se articula en torno a la denominada "nulidad objetiva y automática", que se resume en considerar nulos los despidos tanto disciplinarios como objetivos adoptados durante el embarazo y también cuando se hayan solicitado y/o se estén ejercitando determinados derechos de conciliación excepto que "se declare la procedencia de la decisión extintiva por motivos no relacionados con el embarazo o con el ejercicio del derecho a los permisos y excedencia señalados". En el caso concreto del embarazo la garantía actúa sin necesidad de comunicar el embarazo a la parte empresarial ni de conocimiento previo por parte de ésta, a diferencia de lo establecido en la Directiva 92/85/CEE, del Consejo, de 19 de octubre de 1992, relativa a la aplicación de medidas para promover la mejora de la seguridad y de la salud en el trabajo de la trabajadora embarazada (en adelante Directiva 92/85/CEE) ${ }^{2}$.

\footnotetext{
${ }^{1}$ Sirva como ejemplo el informe "¿Existe <penalización> por maternidad?", elaborado en 2019 por el Observatorio Mujer e Igualdad de la Fundación Promoción Social (https://promocionsocial.org/wpcontent/uploads/2019/06/CONCLUSIONES_EXISTE-PENALIZACION-POR-MATERNIDAD.pdf, consultada el 5 de noviembre de 2019). En la página 120 de sus Conclusiones se afirma que "las mujeres con edades entre 16 y 34 años que tienen hijos ven aumentar sus posibilidades de entrar en desempleo de forma notable". Basándose en los datos extraídos de la Muestra Continua de Vidas Laborales, elaborada por la Seguridad Social, se determina que las mujeres con hijos de entre 18 y 24 años tenían en 2010 una probabilidad de quedar desempleadas superior en 50,70 puntos porcentuales respecto a las que no tienen hijos y de 46,52 puntos porcentuales en 2015, siendo similares, aunque algo inferiores los porcentajes para las mujeres de edades comprendidas entre 25 y 34 años.

2 Interesa recordar que el artículo 2 de esta norma define el concepto "trabajadora embarazada" como "cualquier trabajadora embarazada que comunique su estado al empresario, con arreglo a las legislaciones y/o prácticas nacionales", y por tanto sólo cuando exista tal comunicación entrarán en juego las restricciones que frente al despido establece el artículo 10 de la misma norma.
} 
El riesgo de pérdida del empleo para las trabajadoras embarazadas es singularmente elevado durante el período de prueba, regulado en el artículo 14 del TRLET, porque durante esta fase contractual ambas partes pueden proceder libremente a la extinción de la relación laboral, conforme lo establecido en el primer párrafo del punto 2 de dicho precepto; una facultad que es especialmente relevante para la parte empresarial ${ }^{3}$, dado que la laboral dispone de la facultad de dimisión durante toda la relación laboral en virtud del artículo 49.1.d de la norma estatutaria ${ }^{4}$. Como ha destacado la doctrina en numerosas ocasiones, la finalidad esencial del período de prueba es comprobar la aptitud y adaptación de la persona recién contratada al puesto de trabajo y a la organización empresarial $^{5}$; una afirmación que también comparte la jurisprudencia ${ }^{6}$. En correspondencia con ello se impone a ambas partes la obligación de "realizar las experiencias que constituyan objeto de la prueba" (artículo 14.1.3 del TRLET) y se introducen otras reglas instrumentales, como la diversificación de su duración en función de la calificación del trabajador o su prohibición cuando ya se haya podido realizar aquella comprobación (artículos $14.1 .1^{\circ}$ y $4^{\circ}$ del TRLET, respectivamente) ${ }^{7}$.

A pesar de la indiscutible finalidad prospectiva del período de prueba existe una consolidada jurisprudencia que permite el desistimiento empresarial durante esa fase sin necesidad de exponer ni acreditar causa alguna, ni tampoco de formalizar la decisión por escrito ${ }^{8}$. Se configura de esta forma una facultad de desistimiento ad nutum, que

\footnotetext{
${ }^{3}$ Así lo ha destacado en múltiples ocasiones la doctrina. Sirva como ejemplo VAL TENA, A. L., Pacto de prueba y contrato de trabajo, Civitas, Madrid, 1998, p. 160. En su opinión, el artículo 14.2 del TRLET, otorga indiscutiblemente un "mayor beneficio" a la parte empresarial "al adquirir temporalmente un derecho excepcional no homologado tras la consolidación de la relación jurídico-laboral".

${ }^{4}$ En lo que refiere a la parte laboral la única diferencia entre la extinción durante el período de prueba y la que se ejercite posteriormente reside en que esta última queda sometida a un preaviso.

${ }^{5}$ Véase, por todos, Gallego MoYA, F., El periodo de prueba en el contrato de trabajo, Aranzadi, Cizur Menor, 2016, pp. 58-60

${ }^{6}$ Sirva como ejemplo la STS de 12 de noviembre de 2007 (recurso 4341/2006), que considera abusiva una cláusula convencional que establece una duración de dos años para el período de prueba porque "el tiempo de prueba debe adecuarse a la finalidad misma de la institución que no es otra que posibilitar el conocimiento recíproco entre las partes del contrato, de manera que el empresario pueda valorar las actitudes del trabajador y la conveniencia de mantener el vínculo contractual asumido". En sentido similar se pronuncian la STS de 20 de julio de 2011 (recurso 152/2010), la STS de 4 de marzo de 2008 (recurso 1210/2007), la STS de 18 de enero de 2005 (recurso 253/2004) y la STS De 25 de noviembre de 2005 (recurso 5064/2004), entre otras muchas.

${ }^{7}$ Para un análisis más detenido de la interconexión existente entre estas reglas consúltese FERNÁNDEZ MÁrquez, O., El periodo de prueba en el contrato de trabajo, Tirant lo Blanch, Valencia, 2014, pp. $22-$ 23.

${ }^{8}$ Basta con reproducir un fragmento del FJ $3^{\circ}$ de la STS de 12 de julio de 2012 (recurso 2789/2011) para ejemplificar esta jurisprudencia: "la libertad de desistimiento durante el periodo de prueba supone que ni el empresario ni el trabajador tienen, en principio, que especificar los motivos del cese, ni acreditar los
} 
resulta paradójica atendiendo a las reglas expuestas en el párrafo anterior ${ }^{9}$; facultad que puede incidir de forma muy negativa sobre las trabajadoras embarazadas, particularmente en los casos donde se tenga conocimiento de su estado tras la formalización del contrato $^{10}$. La tutela en este singular contexto se ha articulado tradicionalmente a través de los mecanismos ordinarios de protección de los derechos fundamentales, dada la inexistencia de instrumentos específicos y la resistencia jurisprudencial a trasladar al período de prueba la garantía reforzada prevista para el despido disciplinario y objetivo.

El Real Decreto-Ley 6/2019, de 1 de marzo, de medidas urgentes para garantía de la igualdad de trato y de oportunidades entre mujeres y hombres en el empleo y la ocupación (en adelante RDL 6/2019) modifica el artículo 14.2 del TRLET incorporando un segundo párrafo de enorme trascendencia, que constituye un importante paso adelante en la protección de las trabajadoras embarazadas durante el período de prueba. El objetivo del presente estudio es intentar clarificar el significado y alcance de este cambio normativo, una tarea que no puede abordarse sin una adecuada contextualización. Así pues, empezaremos exponiendo las reglas con las que tradicionalmente se ha abordado el problema, para analizar en un segundo momento un fallido intento de mejora y, finalmente, estudiaremos el nuevo régimen que introduce el RDL 6/2019.

\section{La solución tradicional: la tutela basada en la presunción por indicios de discriminación}

El TC se enfrentó por primera vez a la a problemática generada por la extinción de la relación laboral de una trabajadora embarazada durante el período de prueba en la STC 94/1984, de 16 de octubre. En el caso de autos se analiza la extinción contractual de una trabajadora que desarrolla tareas de técnica sanitaria en una clínica gallega, habiendo prestado servicios anteriormente en otras dos con buenos informes de sus superiores jerárquicos. La relación laboral se inicia el 1 de marzo de 1982, pactándose un período de prueba de tres meses, y diez días después inicia una baja por incapacidad laboral a

hechos o circunstancias determinantes del mismo, ni tampoco expresar la decisión extintiva mediante una forma preestablecida".

Que la forma escrita no sea obligatoria no implica que no se requiera "por su trascendencia y carácter receptivo una expresión indubitada de su contenido" (GALLEGO MOYA, El período..., p. 351) y que a efectos estratégicos la forma escrita sea la preferible, por la seguridad jurídica que aporta.

${ }^{9}$ Así lo han destacado diversos estudios, como por ejemplo RODRÍGUEZ-PIÑERO ROYO, M., "El período de prueba", Revista Española de Derecho del Trabajo, número 100, 2000, p. 476.

10 Cuando el estado de embarazo se conozca ya en la fase precontractual lo más probable, desgraciadamente, es que la discriminación se produzca en ese momento y no llegue a formalizarse la relación laboral. 
consecuencia de una amenaza de aborto, que finalmente se produce el 13 de marzo. El 23 de marzo se la despide argumentando que no ha superado el período de prueba. Consta acreditada la existencia de un informe de la Directora de Enfermeras, emitido el día previo al despido, donde se deja constancia de su "falta de adaptación al sistema de trabajo en el Centro, así como por el carácter brusco con los enfermos y falta de amabilidad". Un informe que se elaboró sin contar con la opinión de la supervisora, que por su contacto directo con el personal era la habitualmente encargada de redactar tales informes y que en esa ocasión se negó a pronunciarse alegando que "no podía dar informe alguno dado el escaso tiempo de trabajo de la actora". La extinción fue declarada nula en primera instancia por la Magistratura de Trabajo número 2 de Vigo en Sentencia de 21 de junio de 1982, posteriormente revocada por la Sentencia del Tribunal Central de Trabajo de 30 de junio de 1983, que declara lícita la extinción.

El principal punto de controversia se planteaba en relación a la posibilidad de proyectar el principio de no discriminación por razón de sexo a la resolución del contrato durante el período de prueba, dadas las singularidades que ésta plantea, y aquí el TC se muestra taxativo señalando, en el Fundamento Jurídico $3^{\circ}$, que "la facultad de resolución de la relación laboral concedida por el artículo 14.2 del Estatuto de los Trabajadores (...) no se puede hacer valer, por causas ajenas al propio trabajo, en contra de un derecho fundamental, como en el presente caso el de igualdad, recogido en el artículo 14 de la Constitución Española"11. Se establece así una primera e importante base para la protección de las trabajadoras embarazadas frente a la extinción contractual durante el período de prueba, aunque la resolución del caso concreto resulta decepcionante y muy criticable. En un contexto como el descrito, donde existen claros indicios de discriminación, el TC termina avalando la licitud de la extinción contractual con argumentos tan poco consistentes como la contratación habitual de mujeres por parte de la clínica o la inexistencia de embarazo cuando se produce la rescisión contractual.

La posterior STC 166/1988, de 26 de septiembre, constituye un importante paso adelante y sienta las bases de una doctrina que se ha mantenido inalterada hasta la aparición del RDL 6/2019. En esta ocasión se analizó la extinción contractual de una trabajadora, también del sector sanitario, contratada con efectos 1 de julio de 1986 para realizar tareas como auxiliar de clínica en sustitución de otras dos trabajadoras durante sus vacaciones de verano. En el contrato se había establecido un período de prueba de quince días y nada más iniciar la prestación la trabajadora manifestó que debido a su estado de embarazo no podía estar en la Sección de Diálisis y solicitó ser enviada a otra

\footnotetext{
${ }^{11}$ Se añade también que el hecho que la resolución contractual durante el período de prueba "no consista en un despido causal fundado en una serie de motivos tasados, sino en una decisión no motivada, no excluye que desde una perspectiva constitucional sea igualmente ilícita una resolución discriminatoria".
} 
sección ${ }^{12}$. Pocos días después, el 7 de julio, la dirección de la empresa le comunicó la resolución del contrato por no haber superado el período de prueba. La Magistratura de Trabajo número 9 de Madrid consideró nula la extinción en su Sentencia de 13 de diciembre de 1986, posteriormente revocada por la del TCT de 12 de mayo de 1987, que avaló la decisión extintiva.

Tras recordar, basándose en la STC 94/1984, de 16 de octubre, la vigencia de la prohibición de discriminación durante el período de prueba, el TC considera aplicable al caso la doctrina sobre "inversión del onus probando" establecida en la STC 38/1981, de 23 de noviembre, y afirma que "ante la presencia de un derecho a no ser discriminada, que la actora alegó informando de su embarazo, la empresa debió explicitar que los motivos que la movieron eran ajenos a tal hecho o situación (...) a justificar la razonabilidad de su conducta resolutoria"; una justificación que en su opinión no se ha aportado, porque no se acredita la imposibilidad de destinarla a otra sección compatible con su estado, ni se le expone ningún argumento en tal sentido, constando acreditado además que la persona sustituida prestaba servicios en la Sección de Cirugía, que sí resultaba compatible. La ausencia de justificación determina la concesión del amparo, con la consecuente declaración de nulidad de la sentencia del TCT y la confirmación de la de instancia.

La configuración definitiva y consolidación de esta doctrina se produce con la STC 17/2007, de 12 de febrero. En ella se analiza el caso de una trabajadora que presta servicios para una empresa telefónica y a la que antes de finalizar una primera relación laboral especial de carácter temporal se le propone suscribir un contrato indefinido. Este último se inicia el 1 de noviembre de 2001 y poco tiempo después la trabajadora queda embarazada en dos ocasiones sucesivas que concluyeron en sendos abortos, uno en el mes de marzo y otro en el mes de mayo de 2002, y comportaron diversas situaciones de baja. Dos días después de emitirse un parte de confirmación de baja, el 3 de junio de 2002, la empresa comunica a la trabajadora la extinción de su contrato por no superación del período de prueba. Tanto la sentencia de instancia como la de suplicación desestiman la impugnación de la trabajadora descartando la existencia de discriminación ${ }^{13}$.

\footnotetext{
${ }^{12}$ Conviene tener presente que en ese momento no existía ninguna norma similar al actual artículo 26 de la Ley 31/1995, de 8 de noviembre, de prevención de riesgos laborales, que obliga a la parte empleadora a adoptar una serie de medidas, incluido el cambio de puesto de trabajo, cuando exista un riesgo que pueda afectar negativamente en la salud de las trabajadoras o del feto.

${ }^{13}$ Son, concretamente, la Sentencia del Juzgado de lo Social número 2 de Bilbao, de 6 de noviembre de 2002 (autos 498/2002) y la STSJ del País Vasco de 11 de marzo de 2003 (recurso 155/2003).
} 
El núcleo de la sentencia se localiza en el último párrafo del Fundamento Jurídico $3^{\circ}$, donde el TC expone y declara aplicable al caso la consolidada doctrina que en ese momento ya tenía elaborada sobre la carga en la prueba en hipótesis de vulneración de derechos fundamentales ${ }^{14}$; una doctrina articulada en torno a dos reglas básicas que han regido la extinción contractual durante el período de prueba de las trabajadoras embarazadas hasta el pasado reciente. Primera: la trabajadora perjudicada debe aportar "un indicio razonable de que el acto empresarial lesiona su derecho fundamental" es decir "un principio de prueba o prueba verosímil dirigido a poner de manifiesto el motivo oculto que se denuncia y que debe permitir deducir la posibilidad de que haya podido producirse". Segunda: una vez acreditados los indicios "incumbe al empresario acreditar que su decisión obedece a motivos razonables y ajenos a todo propósito atentatorio del derecho de que se trate".

La proyección de esas reglas sobre el caso analizado lleva a declarar la nulidad de la extinción porque el TC considera que el relato de hechos probados pone de manifiesto "un panorama indiciario del que surgía, al menos, la sospecha razonable de la eventual relación de causa a efecto entre las bajas laborales ocasionadas por su estado de embarazo y la decisión empresarial de prescindir de sus servicios" y no se han acreditado causas que permitan "destruir la apariencia discriminatoria creada" 15 . Se considera especialmente determinante que hasta el momento previo a las bajas no hubiese quejas del rendimiento de la trabajadora y que se le hubiese propuesto el paso a un contrato indefinido ordinario antes de agotar la relación temporal previa, como también la ilicitud del período de prueba en el que intenta fundamentarse la extinción ${ }^{16}$. Por todo ello se acaba declarando la nulidad de la extinción y se anulan tanto la sentencia de instancia como la de suplicación.

\footnotetext{
${ }^{14}$ Véanse, entre otras, la STC 92/2002, de 11 de febrero (FJ $5^{\circ}$ ), la STC 30/2002, de 11 de febrero (FJ $3^{\circ}$ ), la STC 17/2003, de 30 de enero (FJ $4^{\circ}$ ) y la STC 342/2006, de 11 de diciembre (FJ 4).

${ }^{15}$ Se descartan, por inconsistentes, los dos argumentos utilizados por las sentencias impugnadas para negar la existencia de discriminación, que son el previo comportamiento no discriminatorio de la parte empresarial en relación a otras trabajadoras embarazadas y la circunstancia que sólo dos de las cuatro bajas determinantes de la extinción fueran por aborto. En relación con el primero se destaca que la actuación previa no es determinante y que, además, en el caso analizado concurren circunstancias específicas (sucesión de embarazos y abortos en un corto período de tiempo). Respecto al segundo se constata que todas las bajas producidas estuvieron directamente vinculadas con su embarazo e incluso se añade que "aun en el supuesto de que sólo dos de las bajas estuvieran relacionadas con el embarazo, tal hecho sería suficiente para mantener el indicio de discriminación".

${ }^{16}$ Resulta obvio que en el caso de autos no podía establecerse un nuevo período de prueba porque la trabajadora ya había desarrollado las mismas funciones en la relación laboral especial previa. Basándose en algunos pronunciamientos previos, el TC destaca que "si bien es cierto que el hecho de que el acto empresarial sea improcedente no implica que sea además discriminatorio, al no derivar automáticamente de su antijuridicidad la vulneración constitucional (...) también es indudable que ese elemento añadía seriedad al panorama indiciario ofrecido por la trabajadora".
} 


\section{Una evolución fallida: la STS de 18 de abril de 2011 (recurso 2893/2010) y la STC 173/2013, de 10 de octubre}

Tanto la jurisprudencia ordinaria como la constitucional tuvieron, en las dos sentencias referidas en el título del presente epígrafe, una magnífica oportunidad de dar un paso adelante significativo en la protección de las trabajadoras embarazadas durante el período de prueba. Las soluciones adoptadas, con importantes discrepancias internas y fuertes críticas doctrinales, conectan directamente con la reforma operada por el RDL 6/2019 sobre el artículo 14 del TRLET, que probablemente no se habría producido si aquéllas hubiesen tenido distinto signo. Procedamos a revisar sucintamente el supuesto de hecho, los criterios adoptados y los argumentos que los sustentaron, así como el sentido y fundamento de las voces discrepantes ${ }^{17}$, porque todos estos elementos son esenciales para la correcta valoración del significado y alcance del reciente cambio normativo.

En el caso de autos, la extinción durante el período de prueba afecta a una trabajadora contratada para realizar tareas de comercial, que disponía de experiencia previa en dicho ámbito. La prestación se inicia el 24 de junio de 2009 mediante un contrato de obra de seis meses de duración en el que se pacta un período de prueba de 2 meses y también un nivel mínimo de ventas que si no se alcanza en dos meses consecutivos puede determinar la extinción contractual. El 4 de agosto la empresa le comunica la extinción del contrato por no haber superado el período de prueba. En ese momento la trabajadora estaba embarazada de dieciséis semanas, sin que se acreditase en sede judicial que la parte empresarial era conocedora de tal circunstancia.

Tanto la demanda de despido formulada por la trabajadora como el posterior recurso de suplicación son desestimados ${ }^{18}$. El recurso de casación aporta como sentencia de contraste un pronunciamiento que en una hipótesis similar aplica la garantía de nulidad objetiva establecida en los artículos 53.4 y 55.5 del TRLET a la extinción acordada durante el período de prueba. La cuestión se resume, por tanto, en dilucidar si procede o no la extensión de esa protección reforzada a la hipótesis que nos ocupa y la respuesta que dan tanto el Tribunal Supremo como el Tribunal Constitucional es negativa.

\footnotetext{
17 Para un análisis más detenido puede consultarse cualquiera de los detallados estudios que se han elaborado sobre dichas sentencias, como por ejemplo LOUSADA AROCHENA, F., "Prohibición de despido de las trabajadoras embarazadas y período de prueba”, Revista de Derecho Social, número 63, 2013, pp. 143-154.

18 SJS núm. 31 de Madrid de 2 de diciembre de 2009 (autos 1.298/2009) y STSJ Madrid de 11 de junio de 2010 (rec. 1357/2010).
} 
El Tribunal Supremo basa su negativa en la imposibilidad de operar una traslación analógica de la garantía establecida para el despido objetivo y disciplinario porque, en su opinión, no se cumplen los requisitos exigidos por el artículo 4.1 del Código Civil. Después de revisar su doctrina sobre el período de prueba, acaba concluyendo que existen diferencias muy significativas entre este supuesto y aquellos otros (libertad de forma sin necesidad de exteriorizar la causa frente a exigencia de forma escrita con expresión de la causa), que impiden acudir a la analogía (FJ $3^{\circ}$ y FJ $4^{\circ}$ ). Pero además considera que "el legislador ha evitado conscientemente incorporar la nulidad cualificada al período de prueba", como prueba el hecho de que no lo hiciese en origen la Ley 39/1999, ni posteriormente la Ley Orgánica 3/2007, de 22 de marzo, para la igualdad efectiva de mujeres y hombres; una opción que considera lógica porque "el derecho constitucional a la no discriminación por razón de sexo de las trabajadoras embarazadas estaba ya preservado suficientemente a través de los mecanismos de tutela clásicos" y la extensión de la protección podría tener el "efecto perverso" de dificultar la contratación de las mujeres en edad fértil (FJ $5^{\circ}$ ).

Descartada la extensión de la garantía de nulidad objetiva se entra a valorar la cuestión desde la denominada "tutela clásica". La no acreditación del estado de embarazo, junto con la extinción contractual de un trabajador varón contratado en condiciones y fecha idénticas y la circunstancia de que no se alcanzasen los objetivos mínimos fijados son, en opinión del Tribunal Supremo, elementos suficientes para descartar la existencia de indicios de discriminación. Así pues, tampoco por esta vía se concede la nulidad reclamada.

La sentencia fue dictada con importantes discrepancias internas evidenciadas en un Voto Particular firmado por seis Magistrados/as ${ }^{19}$ y recurrida en amparo ante el Tribunal Constitucional. La STC 173/2013, de 10 de octubre, deniega el amparo considerando que el razonamiento del Tribunal Supremo "satisface plenamente las exigencias de canon de razonabilidad y motivación reforzadas del derecho fundamental a la tutela judicial efectiva (artículo 24.1 CE), que impone la afectación del derecho a la no discriminación por razón de sexo ( artículo 14 CE)", destacando que este último queda perfectamente garantizado durante el período de prueba con el mecanismo

\footnotetext{
${ }^{19}$ Concretamente Fernando Salinas Molina, Luis Fernando de Castro Fernández, Jordi Agusti Julià, María Luisa Segoviano Astaburuaga, Rosa Maria Viroles Piñol y Manuel Ramon Alarcon Caracuel. El argumento central del Voto Particular, se resume en considerar que una vez el legislador ha optado por otorgar a las trabajadoras embarazadas una protección objetiva frente al despido, reforzando el derecho a la no discriminación por razón de sexo, debe otorgarse "idéntica protección" a las extinciones contractuales durante el período de prueba, que sólo deberían resultar válidas cuando la parte empresarial acreditase que "no tienen ninguna relación con el embarazo y que, en su caso, responden a una causa procedente, real, suficiente y seria".
} 
genérico de protección de derechos fundamentales basado en la distribución de la carga de la prueba, que en el caso analizado se considera correctamente valorado y aplicado ${ }^{20}$.

También esta sentencia tiene Votos Particulares, concretamente dos. El más destacable es sin duda el segundo ${ }^{21}$, que defiende la extensión de la nulidad objetiva a las extinciones producidas durante el período de prueba argumentando que la valoración debe efectuarse desde la óptica del derecho sustantivo, esto es, del artículo $14 \mathrm{CE}$, que no admite "interpretaciones que diferencien la tutela antidiscriminatoria entre situaciones que precisen, por razón de embarazo, la misma protección".

La jurisprudencia que se acaba de comentar fue objeto de severas críticas por parte de la doctrina mayoritaria ${ }^{22}$, que consideró más consistentes los argumentos utilizados por los votos particulares, valorando de forma muy negativa las distorsiones que generaba la existencia de dos sistemas distintos de tutela antidiscriminatoria para un mismo supuesto de hecho y la incongruencia de exigir "que se busque el móvil discriminatorio en supuestos en los que la protección es per se menor que en el caso del despido y en los que la prueba es aún mucho más dificultosa"23. Incluso se apuntó la difícil compatibilidad con la Directiva 92/85/CEE 1legando a vaticinar "la futura defunción de la doctrina constitucional" ${ }^{24}$, que finalmente ha llegado, pero por una vía distinta.

\footnotetext{
${ }^{20}$ El FJ $6^{\circ}$ asume en este punto el razonamiento efectuado por el TS y afirma que el caso de autos se diferencia claramente del analizado en la STC 17/2007, de 12 de febrero, donde sí se aportaron indicios racionales de discriminación.

${ }^{21}$ Formulado por Fernando Valdés Dal-Ré, al que se adhieren Adela Asua Batarrita, Luis Ignacio Ortega Álvarez y Juan Xiol Ríos.

22 Véanse, por ejemplo, PÉREZ DEL PRADO, D., "La heterogénea tutela antidiscriminatoria de la trabajadora embarazada. La STC 173/2013 y la delimitación de los ámbitos de menor protección", Información Laboral, número 1, 2014, pp. 3-4 (versión electrónica); LOUSADA AROCHENA, "Prohibición de despido...", pp. 152-154; CARRASCO DURÁN, M., "La jurisprudencia constitucional sobre discriminación por embarazo en el ámbito de las relaciones laborales", Actualidad Jurídica Aranzadi, número 875, 2013, p. 2 (versión electrónica); BAJO GARCÍA, I.: "Embarazo y nulidad objetiva de la extinción del contrato durante el período de prueba", Revista General de Derecho del Trabajo y de la Seguridad Social, número 36, 2014, pp. 182-88 y GALLEGO MOYA, El período de prueba, p. 407-410. En sentido contrario, considerando "más apropiada conforme a derecho" la posición adoptada por el Pleno del Tribunal Constitucional, se manifiesta TALÉNS VISCONTI, E., "Extinción del contrato de una trabajadora embarazada durante el período de prueba. Comentario a la STC (Pleno) 173/2013, de 10 de octubre", Revista Bolivariana de Derecho, número 18, 2014, p. 848.

${ }^{23}$ PÉREZ DEL PRADO, "La heterogénea tutela...”, p. 3.

${ }^{24}$ LOUSADA AROCHENA, "Prohibición de despido...", p. 154.
} 


\section{La corrección normativa a través del RDL 6/2019}

\subsection{Primera aproximación: la extensión al periodo de prueba de la garantía de nulidad objetiva y automática}

El actual párrafo $2^{\circ}$ del artículo 14.2 del TRLET, incorporado por el RDL 6/2019, establece que "La resolución a instancia empresarial será nula en el caso de las trabajadoras por razón de embarazo, desde la fecha de inicio del embarazo hasta el comienzo del período de suspensión a que se refiere el artículo 48.4, o maternidad, salvo que concurran motivos no relacionados con el embarazo o maternidad".

A pesar de la indiscutible trascendencia de este nuevo párrafo, no hallamos en la Exposición de Motivos del Real Decreto-Ley 6/2019 ninguna referencia expresa al mismo, más allá de las declaraciones genéricas sobre la necesidad de articular las "garantías necesarias para hacer efectivo el principio de igualdad de trato" o de eliminar "la discriminación por el embarazo"25. Aún así resulta evidente, atendiendo a los antecedentes jurisprudenciales expuestos en el epígrafe anterior y al marcado paralelismo que la regla transcrita mantiene con los artículos 53.4 y 55.5 del TRLET, que la reforma normativa pretende extender a la extinción durante el período de prueba la garantía de nulidad objetiva y automática que Ley 39/1999 estableció para el despido disciplinario y objetivo, corrigiendo la posición adoptada por la STS de 18 de abril de 2011 (recurso 1398/2011) y la STC 3773/2011, de 10 de octubre ${ }^{26}$. Y ello es muy importante en la interpretación del artículo 14.2.2 $2^{\circ}$ del TRLET, porque permite acudir a los criterios jurisprudenciales dictados sobre aquellos otros preceptos estatutarios para concretar el significado y alcance de este último. Procedamos pues a definir, desde esta perspectiva y con la máxima precisión posible, las piezas que conforman la nueva garantía.

\footnotetext{
${ }^{25}$ Resulta sorprendente que en los párrafos de la Exposición de Motivos del RDL 6/2019 dedicados a comentar los cambios introducidos por el artículo 2 de dicha norma, entre los cuales figura la modificación del artículo 14.2 del TRLET, sólo se haga referencia a los que inciden sobre la conciliación de la vida laboral y familiar y sobre la igualdad retributiva.

${ }^{26}$ En este punto coinciden todos los análisis del Real Decreto-Ley 6/2019, habiéndose afirmado que la norma reformadora "neutraliza" la doctrina del TC y el TS (BALLESTER PASTOR, M. A., "El RDJ 6/2019 para la garantía de la igualdad de trato y de oportunidades entre mujeres y hombres en el empleo y la ocupación: dios y el diablo en la tierra del sol", Temas Laborales, número 146/2019, p. 39) y que constituye "una respuesta" a la misma (FABREGAT MONFORT, G., "Las novedades en materia de igualdad de género en el mercado de trabajo", Revista General de Derecho del Trabajo y de la Seguridad Social, número 53, 2019, p. 335, nota a pie número 7).
} 


\subsection{El ámbito subjetivo de la garantía: identificación del colectivo beneficiario}

El primer elemento que interesa definir es el ámbito subjetivo de la garantía, esto es, las concretas trabajadoras que se benefician de ella. La redacción del artículo 14.2.2 $2^{\circ}$ del TRLET no es demasiado afortunada en este punto, porque opta por la expresión "trabajadoras por razón de embarazo" en lugar de utilizar "trabajadoras embarazadas", una fórmula más clara que coincidiría con la empleada en los artículos 53.4.b y 55.5.b del TRLET ${ }^{27}$. La amplitud de aquella expresión ha llevado a considerar que "quizás se ha querido incluir en la protección a trabajadoras en tratamiento de fertilidad"28, una extensión de cobertura oportuna, pero en mi opinión difícil de defender si atendemos a la finalidad no declarada de la modificación normativa que nos ocupa.

Aunque la fórmula legal para identificar el colectivo beneficiario de la nueva garantía no sea la más idónea, resulta claro que se proyecta sobre las trabajadoras embarazadas mientras se mantenga tal estado, esto es, desde la fecha de inicio del embarazo -como expresamente indica la norma- hasta su final -indirectamente identificado con la referencia a la suspensión del artículo 48.4 del TRLET. No quedan cubiertas, en consecuencia, las extinciones acordadas durante el período de prueba de trabajadoras que se hallan en alguna de las restantes situaciones a las que se extiende la garantía en las hipótesis de despido, donde la tutela deberá instrumentarse a través de la vía ordinaria en supuestos de vulneración de derechos fundamentales, esto es, la aportación de un panorama indiciario que fuerce a al parte empresarial a acreditar la razonabilidad de la extinción.

Conviene detenerse un momento en el límite de cobertura apuntado, porque puede generar algunos problemas aplicativos relevantes. Adviértase, de entrada, que son

\footnotetext{
${ }^{27}$ Resulta oportuno en este punto traer a colación una reflexión contenida en el FJ $8^{\circ}$ de la STC 92/2008, de 21 de julio, en relación a una expresión muy similar -"despido motivado por razón de embarazo"- que figura en la Exposición de Motivos de la Ley 31/1999. El TC admite que esa fórmula resulta un tanto confusa y puede poner en duda el carácter objetivo y automático de la garantía introducida en los artículos 53.4 y 55.5 del TRLET, pero la explica argumentando que "la finalidad esencial de la norma es la de combatir los despidos discriminatorios, los despidos <motivados $>$ por razón de embarazo (...) y es lógico que así lo resalte el texto en el que se exponen los motivos de la norma". La pretensión básica del nuevo párrafo $2^{\circ}$ del artículo 14.2 del TRLET es la misma y desde esa lógica debe interpretarse la defectuosa redacción que delimita el ámbito subjetivo.

${ }^{28}$ Así lo apunta Agustí Maragall, J., "Igualdad, conciliación y maternidad. Análisis crítico de las principales novedades en el Real decreto-ley 6/2019”, ponencia presentada a las XIII Xornadas de Outono sobre "El Modelo Social Europeo", celebradas el 22 y 23 de noviembre de 2019 (en fase de publicación como capítulo del libro colectivo del evento por la editorial Francis Lefevbre), p. 37.
} 
muchas las situaciones excluidas ${ }^{29}$, aunque en algunas de ellas la existencia de un estado de embarazo permite defender con consistencia la aplicación de la garantía (así por ejemplo en la suspensión por riesgo durante el embarazo, prevista en el artículo 45.1.d del TRLET). Más complejos son los problemas que pueden plantearse en relación a la suspensión por nacimiento de hijo, dado que el artículo 48.4 del TRLET permite "anticipar su ejercicio hasta cuatro semanas antes de la fecha prevista del parto" y si la trabajadora hace uso de tal posibilidad se situará fuera del ámbito protegido por la garantía, al menos desde una interpretación literal del artículo 14.2.2 $2^{\circ}$ del TRLET.

Un problema distinto, que queda fuera de nuestro objeto de estudio, pero no podemos dejar de apuntar, es qué debe entenderse por "maternidad". La cuestión es particularmente compleja, porque en la actual redacción del artículo 48.4 del TRLET, fruto de la misma reforma normativa, ya no se utiliza ese término, que ha sido sustituido por "nacimiento". En función de la respuesta que se dé a esta cuestión podrían resolverse indirectamente algunos de los problemas señalados en el párrafo anterior. Se ha apuntado que "con el obsoleto término <maternidad $>$ (...) el legislador ha querido explicitar con toda claridad que la tutela alcanza sólo a la madre biológica durante el permiso de 16 semanas, y que, por consiguiente, no alcanzaría al progenitor/a no biológico (como tampoco a las situaciones de adopción o acogimiento" 30 , y probablemente ésta sea la interpretación más consistente.

Para completar la delimitación del ámbito subjetivo conviene destacar la irrelevancia del conocimiento empresarial. La declaración de nulidad repercute sobre cualquier desistimiento empresarial durante el período de prueba que afecte a una trabajadora embarazada, con independencia de si la contraparte empleadora tiene o no conocimiento de tal circunstancia en el momento de la extinción, e incluso del conocimiento de la propia afectada. Los argumentos que en su momento llevaron a la STC 92/2008, de 21 de julio, a alcanzar esa misma conclusión en relación a los artículos 53.4 y 55.5 del TRLET son perfectamente aplicables al artículo $14.2 .2^{\circ}$ de la misma norma, dada la

\footnotetext{
${ }^{29}$ Tales situaciones son: 1) la suspensión por nacimiento, adopción, guarda con fines de adopción, acogimiento, (artículo 45.1.d del TRLET); 2) la suspensión por riesgo durante el embarazo o riesgo durante la lactancia natural (artículo 45.1.e del TRLET); 3) la suspensión por incapacidad temporal derivada de "enfermedades causadas por embarazo, parto o lactancia"; 4) la solicitud y disfrute de los derechos previstos en los artículos 37.4, 37.5 y 37.6 del TRLET; 5) la solicitud y disfrute de la excedencia prevista en el artículo 46.3 del TRLET; 6) todas aquellas en las que se encuentren las trabajadoras víctimas de violencia de género por el ejercicio de su derecho a la tutela judicial efectiva o de los derechos que les atribuye el TRLET para hacer efectiva su protección y su derecho a la asistencia social integral; y 7) la reintegración al trabajo tras el disfrute de la suspensión prevista en el artículo 45.1.d) del TRLET, durante un período de doce meses a contar desde la fecha del nacimiento, la adopción, la guarda legal o el acogimiento.

${ }^{30}$ Agustí MARAGALl, “Igualdad y conciliación...”, p. 38.
} 
directa conexión que existe entre ellos ${ }^{31}$. Coinciden en este punto la mayoría de los análisis del RDL 6/2019 32 .

\subsection{El alcance objetivo de la garantía: la presunción "iuris tantum" de nulidad}

La segunda pieza a concretar es el alcance objetivo de la garantía. La nueva regla legal establece que "será nula" la resolución contractual de una trabajadora embarazada durante el período de prueba "salvo que concurran motivos no relacionados con el embarazo", una fórmula que en opinión de un sector doctrinal introduce una "presunción iuris tantum" de nulidad ${ }^{33}$. Comparto plenamente esta lectura, porque es la que mejor encaja en la letra del 14.2.2 $2^{\circ}$ del TRLET y también la más lógica atendiendo al paralelismo que dicho precepto mantiene con los artículos 53.4 y 55.5 del TRLET.

Ahora bien ¿cuáles pueden ser esos "motivos no relacionados con el embarazo"? Teniendo presente que, según se expuso y argumentó en el primer epígrafe, el período de prueba tiene una indiscutible finalidad prospectiva, tales motivos deben vincularse necesariamente al desempeño de la trabajadora embarazada en el puesto de trabajo que ocupe, quedando rota la presunción $\mathrm{y}$, consecuentemente, justificada la extinción cuando se verifique un problema concreto de falta de capacidad, competencia y/o adaptación.

A diferencia de los supuestos de despido disciplinario y objetivo, no existe en este caso una delimitación normativa ni convencional de la causa que debe acreditar la parte empresarial, pero ni esta circunstancia ni la discrecionalidad que tradicionalmente se ha reconocido a la parte empresarial para ejercer el desistimiento durante el período de prueba son argumentos suficientes para reducir la exigencia respecto a las razones necesarias para romper la presunción. Se requiere una motivación concreta o específica vinculada al desempeño profesional, porque si bastase una alegación genérica del tipo "no se han cumplido los objetivos previstos" o "el rendimiento no es satisfactorio" se

31 Tales argumentos, recogidos en el FJ $8^{\circ}$ de dicha sentencia, se resumen en dos: primero, la interpretación literal, dado que no se exige expresamente el conocimiento de la parte empresarial y, además, al delimitar el ámbito temporal de la garantía se hace referencia a "la fecha de inicio del embarazo"; segundo, la interpretación contextual vinculada a la "necesaria finalidad de innovación del ordenamiento jurídico que debe perseguir toda reforma legal", perspectiva que lleva a descartar una exigencia que sólo tiene sentido en el sistema de protección precedente.

32 Véanse PAStor Martínez, A., "Las medidas laborales del Real Decreto-Ley 6/2019, de 1 de marzo, de medidas urgentes para garantía de la igualdad de trato y de oportunidades entre mujeres y hombres en el empleo y la ocupación: un paso hacia la efectividad de la igualdad de trato y de oportunidades desde la corresponsabilidad", IUSLabor, núm. 1/2019, p. 196; BALLESTER PASTOR, "El RDL 6/2019 para la garantía...”, p. 39 y AGUSTÍ MARAGALL, "Igualdad y conciliación...”, p. 38.

${ }^{33}$ PASTOR MARTínEZ, “Las medidas laborales...”, p. 196. 
vaciaría de contenido la garantía que pretende articular la presunción de nulidad. El efecto último de la reforma normativa es situar como punto de partida un escenario muy similar al que anteriormente se planteaba tras la aportación suficiente de indicios de discriminación, de forma que los criterios jurisprudenciales previos sobre la justificación razonable de la actuación empresarial pueden ofrecer valiosas orientaciones para delimitar los "motivos razonables" referidos en el artículo 14.2.2 $\mathrm{del}$ TRLET.

En directa conexión con lo señalado en el apartado anterior, conviene apuntar la posibilidad de estipular, en el mismo acuerdo que establezca el período de prueba o por otra vía, un resultado o rendimiento mínimo para objetivar la decisión empresarial y ofrecer mayor seguridad jurídica a ambas partes contractuales ${ }^{34}$.

En el nuevo contexto generado por el artículo $14.2 .2^{\circ}$ del TRLET cobra importancia la regla sobre cómputo del período de prueba fijada en el segundo párrafo del artículo 14.3 de la misma norma, también afectado por el RDL 6/2019, pero con modificaciones puramente terminológicas. En virtud de dicho párrafo determinadas situaciones de suspensión contractual, entre las que figuran algunas que pueden plantearse con cierta frecuencia en la hipótesis que nos ocupa (las de riesgo durante el embarazo e incapacidad temporal $)^{35}$, no interrumpen el cómputo del período de prueba excepto que se produzca acuerdo entre las partes. Pues bien, si el tiempo de prueba establecido sigue

${ }^{34}$ La cuestión se plantea indirectamente en el caso tratado por la STS de 18 de abril de 2011 (rec. $2893 / 2010$ ) y la STC $173 / 2013$, de 10 de octubre, que ha sido objeto de comentario en el epígrafe precedente. Interesa recordar que en tal supuesto el mismo contrato que establecía el período de prueba para una trabajadora que realizaba tareas de comercial fijaba un volumen mínimo de ventas referenciado en períodos bimensuales. Concretamente exigía la obtención de una comisión mínima de 240 euros cada dos meses, habiéndose fijado la cuantía de ésta en el 5 por 100 del importe de las ventas realizadas. Cuando no se alcanzase ese mínimo durante dos meses consecutivos se produciría la extinción de la relación laboral. Aunque no se indique expresamente, parece obvio que era un pacto suscrito al amparo del artículo 49.1.b del TRLET y no una pauta objetiva introducida en relación a la superación del período de prueba, pero aún así tanto el Tribunal Supremo como el Tribunal Constitucional le otorgan relevancia, considerando que el hecho de no haber alcanzado ese objetivo mínimo es un elemento más (junto a la no acreditación del conocimiento del estado de embarazo por la parte empresarial) para descartar la existencia de indicios suficientes de discriminación (véase el FJ $6^{\circ}$ de ambas sentencias). La cuestión generó, además, una cierta controversia porque el Voto Particular de la primera sentencia destaca que la trabajadora no llega a trabajar dos meses (la extinción se produce el 4 de agosto y se había iniciado el 24 de junio) y que las cantidades efectivamente percibidas en concepto de comisiones no se corresponden con las que derivarían de la cifra de ventas conseguidas (siendo esta última de 4.615 euros debería haber cobrado 120 euros, cuando el realidad se le pagaron 245,06 euros, 524,260 euros y 294,470 euros los meses de junio, julio y agosto, respectivamente).

${ }^{35}$ También se incluyen otras que aun pudiéndose plantear durante el embarazo serán menos habituales en la práctica, como la suspensión por adopción, guarda con fines de adopción o acogimiento, la suspensión por violencia de género y la suspensión por riesgo durante la lactancia. 
corriendo, aunque no haya prestación efectiva de servicios $\mathrm{y}$, en consecuencia, no puedan realizarse las experiencias propias de tal fase contractual, la parte empresarial no podrá recabar las evidencias sobre la falta de capacidad o adecuación necesarias para romper la presunción de nulidad. El efecto último es un reforzamiento indirecto de la nueva garantía, por cuanto se dificulta -y en algunos casos incluso puede llegar a impedirse- la extinción a instancia empresarial en período de prueba cuando no haya habido una prestación efectiva de servicios significativa durante el mismo.

\subsection{La eventual incidencia sobre la mecánica extintiva: ¿obligación de comunicación escrita con especificación causal?}

Tal como se recordó en el primer epígrafe, existe una consolidada jurisprudencia que permite el desistimiento empresarial durante el período de prueba sin necesidad de exponer causa alguna ni tampoco de respetar una determinada forma. ¿Cabe entender que el nuevo párrafo $2^{\circ}$ del artículo 14.2 del TRLET determina la modificación de esta jurisprudencia forzando la comunicación escrita con especificación causal cuando la decisión afecte a una trabajadora embarazada?

La respuesta depende de la posición que se adopte en relación al momento en que deben alegarse y acreditarse los motivos que justifican el desistimiento empresarial. A mi modo de ver, no es imprescindible hacerlo cuando se comunica la extinción. La presunción de nulidad puede destruirse también en la fase preprocesal o procesal, una vez impugnada la extinción por la parte laboral. Defender lo contrario llevaría al absurdo de imponer la nulidad en supuestos donde la parte empleadora tiene sólidas razones para fundamentar su desistimiento y no las ha hecho valer porque desconocía el estado de embarazo.

Aunque la reforma normativa que nos ocupa no imponga la comunicación escrita con especificación causal a los desistimientos empresariales durante el período de prueba que afecten a trabajadoras embarazadas, la exigencia de esta forma extintiva sí puede encontrar fundamento, en determinadas hipótesis, en el artículo 10.2 de la Directiva 92/85/CEE, donde se establece que "Cuando se despida a una trabajadora, a que se refiere el artículo 2, durante el periodo contemplado en el punto 1, el empresario deberá dar motivos justificados de despido por escrito". El Tribunal de Justicia de la Unión Europea ha tenido oportunidad de pronunciarse en diversas ocasiones sobre el alcance de esta regla, destacando la necesidad de informar a la trabajadora embarazada de las razones concretas que motivan la extinción; una exigencia que en los supuestos de despido colectivo incluye la indicación de "los criterios objetivos que se han seguido para la designación de los trabajadores afectados por el despido" (apartado 54 de la STJUE de 22 de febrero de 2018, C-103/16 -Asunto Porras Guisado-). La literalidad de 
la regla deja clara su transcendencia, pero ¿resulta aplicable a los desistimientos empresariales en período de prueba que afectan a trabajadoras embarazadas?

En mi opinión la respuesta debe ser afirmativa con alguna matización, por las razones que de inmediato paso a detallar analizando dos aspectos directamente relacionados en los que reside la clave de la cuestión: primero, el significado de los conceptos "despido" y "trabajadora embarazada" en el ámbito de la Directiva 92/85/CEE; segundo, la eficacia del artículo 10.2 de dicha norma en ausencia de transposición.

La interpretación del término "despido" en el contexto de la Directiva 92/85/CEE es una cuestión compleja, porque dicha norma no ofrece ninguna definición del mismo, a diferencia de lo que sucede con otros conceptos importantes que sí aparecen delimitados en su artículo 2. Ante ese silencio y la ausencia de una remisión expresa a las legislaciones y/o prácticas nacionales en lo que refiere a tal definición, cabe entender que nos hallamos ante un concepto de Derecho de la Unión, que no debe coincidir necesariamente con los manejados por los ordenamientos de los Estados miembros y que deberá concretarse atendiendo esencialmente a la finalidad del artículo 10 de la Directiva 92/85/CEE. Una simple lectura de dicho precepto basta para concluir que su pretensión es proteger a las trabajadoras embarazadas y a las que estén disfrutando de un permiso por maternidad frente a las extinciones contractuales adoptadas a iniciativa de la parte empresarial, con independencia de la calificación formal que éstas merezcan conforme al derecho interno aplicable.

Este entendimiento específico y amplio del concepto "despido" ha sido claramente asumido en la STJUE de 11 de noviembre de 2010 (C-232/09, asunto Danosa), donde se analiza el caso de una trabajadora integrada en el Consejo de dirección de una empresa societaria ubicada en Letonia que es destituida mediante un acuerdo de la junta de socios adoptado en virtud del artículo 224.4 del Código de comercio letón, donde se establece que "Los miembros del Consejo de dirección podrán ser sustituidos por acuerdo de los socios", en cualquier momento y sin requerir ninguna causa concreta. El TJUE entra a valorar si en tal caso se han cumplido las garantías establecidas en el artículo 10 de la Directiva 92/85/CEE sin cuestionarse que nos hallemos ante un "despido", porque presupone que una rescisión unilateral del vínculo jurídico sobre el que se articula la prestación de servicios a iniciativa de la contraparte encaja en ese concepto $^{36}$.

\footnotetext{
${ }^{36}$ Resulta significativo que la consideración de la destitución acordada por la Junta de accionistas como un despido en el sentido del artículo 10.2 de la Directiva 92/85/CEE tampoco genere dudas al órgano judicial remitente, que no interroga ni directa ni indirectamente sobre tal aspecto. Sí se pregunta, por el contrario, respecto a la condición de trabajadora de la Sra. Danosa, concluyendo el TJUE que "Los miembros de un Conejo de dirección de una sociedad de capital, que prestan servicios en ésta y forman
} 
En base a la sentencia citada en el párrafo anterior resulta obligado concluir que el desistimiento empresarial durante el período de prueba debe considerarse un "despido" a efectos del artículo 10 de la Directiva 92/85/ $\mathrm{CEE}^{37}$; una conclusión que queda reforzada si atendemos a la amplitud con que el TJUE tiende a interpretar ese mismo concepto en otros contextos normativos, como por ejemplo la Directiva 1998/59/CE, de 20 de julio, del Consejo, sobre aproximación de las legislaciones de los Estados miembros que se refieren a despidos colectivos ${ }^{38}$.

Bastante más fácil es la delimitación del concepto "trabajadora embarazada", porque el artículo 2.a) de la Directiva 92/85/CEE lo define señalando que deberá entenderse como tal "cualquier trabajadora que comunique su estado al empresario, con arreglo a las legislaciones y/o prácticas nacionales". En virtud de tal definición la comunicación del estado de embarazo a la parte empresarial es necesaria para ostentar aquella condición, aunque el TJUE ha precisado que también debe reconocerse "si el empleador, sin haber sido informado formalmente del embarazo de la trabajadora por la propia interesada, tuviese conocimiento del embarazo de ésta", porque de lo contrario se estaría llevando a cabo una interpretación excesivamente restrictiva, contraria al espíritu y finalidad de la

parte integrante de ella tienen la condición de trabajadores, a efectos de la Directiva 92/85/CEE, si su actividad se ejerce, durante un tiempo determinado, bajo la dirección y control de otro órgano de esta sociedad y si, a cambio de esta actividad, perciben una retribución".

${ }^{37}$ Adviértase que existe una notable similitud entre la hipótesis extintiva analizada en la STJUE de de 11 de noviembre de 2010 (C-232/09, asunto Danosa) y la prevista en el artículo 14.2 del TRLET, no sólo porque tengan origen en la voluntad empresarial sino porque la norma que las regula no requiere, en principio, que concurra ninguna causa justificativa.

La aplicación del artículo 10 de la Directiva 92/85/CEE a las extinciones producidas a instancia empresarial durante el período de prueba es compartida por BALLESTER PASTOR, M. A., "El significado de la tutela efectiva contra el despido de la trabajadora embarazada. Lo que dice y lo que quiere decir la STJUE de 22 de febrero de 2018, asunto Porras Guisado", Trabajo y Derecho, número 45, 2018, p. 11 y LOUSADA ARochenA, "Prohibición de despido...", p. 154.

${ }^{38}$ Conviene recordar que en este contexto el concepto "despido", también faltado de definición expresa, se ha interpretado de forma amplia por el TJUE, llegando a incluir los supuestos donde la parte empresarial "proceda, unilateralmente y en perjuicio del trabajador, a una modificación sustancial de elementos esenciales del contrato de trabajo por motivos no inherentes a la persona del trabajador". Así se establece en el apartado 55 de la STJUE de 11 de noviembre de 2015 (C-422/14, asunto Pujante Rivera), posteriormente precisado por la STJUE de 21 de septiembre de 2017 (C-149/16, asunto Socha) y la STJUE de 21 de septiembre de 2017 (C-429/16, asunto Sciupa). Para una valoración detenida del alcance y repercusión de esta amplia interpretación puede consultarse alguno de los numerosos análisis doctrinales existentes al respecto, como por ejemplo los de AgUSTí MARAGALL, J., "Despido colectivo. Un concepto en constante evoluación", ponencia presentada en las Jornadas por el Consejo General del Poder Judicial sobre "Doctrina judicial del Tribunal de Justicia de la Unión Europea y del Tribunal Supremo. Discrepancias interpretativas" (CU 19076), celebradas en Madrid los días 10 a 12 de junio de 2019; o de GonZÁlez GonZÁleZ, C., "Modificaciones de las condiciones de trabajo y su incidencia en el cómputo de los umbrales del despido colectivo en la doctrina del Tribunal de Justicia de la Unión Europea", Aranzadi Doctrinal, número 4, 2018. 
norma europea (apartado 55 de la SJUE de 11 de noviembre de 2010, C232/09 -Asunto Danosa- $)^{39}$. Así pues y en lo que atañe a la hipótesis que nos ocupa, la obligación de formalizar el desistimiento en período de prueba por escrito y especificando la causa motivadora no operará en todos los casos donde la afectada sea una trabajadora embarazada, sino que quedará limitada, ya de entrada, a los supuestos donde la parte empresarial conozca el estado de embarazo, porque la trabajadora se lo ha comunicado o porque ha adquirido consciencia del mismo por cualquier otra vía.

Ahora bien, una vez concluido, primero, que la extinción a instancia empresarial de la relación laboral de una trabajadora embarazada durante el período de prueba constituye un despido en el sentido del artículo 10.2 de la Directiva 92/85/CEE, y segundo, que el conocimiento de tal estado activa la obligación de "dar motivos justificados de despido por escrito", resulta imprescindible dar un paso más y plantearse si esta obligación es directamente aplicable, dado que no ha sido incorporada al ordenamiento jurídico español $^{40}$. En mi opinión y atendiendo a la consolidada doctrina del TJUE sobre la eficacia de las directivas no transpuestas, la respuesta debe ser positiva, por las razones que de inmediato paso a detallar.

Como es bien sabido y ha señalado en múltiples ocasiones el $\mathrm{TJUE}^{41}$, las directivas no pueden crear por sí solas obligaciones a cargo de un particular, pero sí vinculan a los Estados miembros, forzándolos a alcanzar los resultados que en ellas se establezcan mediante la adopción de "todas las medidas generales o particulares apropiadas para asegurar el cumplimiento de dicha obligación"42. Tal vinculación se extiende a todas las autoridades estatales, incluidas las judiciales, que están obligadas a interpretar las normas internas "a la luz de la letra y de la finalidad de la directiva de que se trate con el fin de alcanzar el resultado que ésta persigue"; el denominado "principio de interpretación conforme", que no puede servir de base para una interpretación "contra

\footnotetext{
${ }^{39}$ Con esta precisión el TJUE impone un importante límite a las legislaciones y/o prácticas nacionales cuando proceden, en virtud de la competencia que les reconoce el mismo artículo 2.a) de la Directiva 92/85/CEE, a definir la forma en que la trabajadora comunica su estado al empleador, desde la premisa que "esta forma no puede vaciar de sustancia la protección especial de la mujer establecida en el articulo 10 de dicha Directiva".

${ }^{40} \mathrm{Ni}$ antes del RDL 6/2019 ni con posterioridad a la entrada en vigor de esta norma existe a nivel legal una regla que requiera expresamente la comunicación por escrito y concretando la causa motivadora de las extinciones acordadas por la parte empleadora durante el período de prueba conociendo el estado de embarazo de la afectada, una regla que, según se razonó al inicio del presente epígrafe, tampoco puede extraerse implícitamente del artículo 14.2.2 ${ }^{\circ}$ del TRLET.

${ }^{41} \mathrm{La}$ doctrina que se expone a continuación aparece recogida en numerosos pronunciamientos del TJUE. Sirva como ejemplo la STJUE de 14 de abril de 2016 (C-441/14, caso DI), a partir de la cual iremos referenciando los criterios que se exponen en este párrafo.

${ }^{42}$ Véanse el apartado 30 de la STJUE de 14 de abril de 2016 (C-441/14, caso DI) y las sentencias allí citadas.
} 
legem" del Derecho nacional pero sí forzar la modificación de un criterio jurisprudencial, aunque esté absolutamente consolidado, si se basa en una interpretación incompatible con los objetivos de una directiva ${ }^{43}$.

Pues bien, como ya se ha destacado en más de una ocasión, la admisión del desistimiento empresarial durante el período de prueba sin necesidad de exponer causa alguna ni de formalizar tal decisión por escrito tiene origen jurisprudencial. El artículo 14.2 del TRLET se limita a señalar que en esa fase de la relación laboral la resolución "podrá producirse a instancia de cualquiera de las partes durante su transcurso" sin añadir ninguna indicación sobre la forma como deber hacerse efectiva y sobre este silencio normativo se ha construido aquel criterio jurisprudencial; un criterio que debe ser corregido en cumplimiento del principio de interpretación conforme para garantizar la consecución del resultado perseguido por el artículo 10.2 de la Directiva 92/85/CEE. Requerir que una parte de las extinciones acordadas por la parte empleadora durante el período de prueba se lleven a cabo por escrito especificando la causa que las fundamenta, no contradice ninguna norma legal ni, consecuentemente, supera los límites de aquel principio interpretativo.

Al margen de que la comunicación escrita con especificación causal sea la forma técnicamente exigible, en base al artículo 10.2 de la Directiva 92/85/CEE, para hacer efectivo el desistimiento cuando la parte empresarial tenga conocimiento del estado de embarazo, también resulta la más oportuna desde un punto de vista estratégico, si se pretende evitar la nulidad presumida por el artículo 14.2.2 ${ }^{\circ}$ del TRLET. Intentar dejar claro desde el primer momento que el desistimiento se fundamenta en razones objetivas es sin duda la mejor forma de romper la presunción y también la más lógica si realmente concurren tales razones. Además, canalizar la decisión extintiva por escrito permitirá a la parte laboral tener un mejor conocimiento de la motivación, facilitará la prueba a la parte empresarial y, en definitiva, otorgará mayor seguridad jurídica.

Finalmente, conviene destacar que la especificación causal efectuada en la comunicación extintiva vincula a la parte empresarial en la posterior fase judicial, donde no podrá alegar motivos distintos para intentar romper la presunción de nulidad. Así se extrae del artículo 105.2 de la $\operatorname{LJS}^{44}$, que resulta de aplicación porque las impugnaciones de los desistimientos empresariales en período de prueba deben

\footnotetext{
${ }^{43}$ Así se establece en los apartados 31 a 33 de la STJUE de 14 de abril de 2016 (C-441/14, caso DI) y en diversos pronunciamientos previos citados en dichos apartados.

${ }^{44}$ Conforme a este artículo "Para justificar el despido, al demandado no se le admitirán en el juicio otros motivos de oposición a la demanda que los contenidos en la comunicación escrita de despido".
} 
canalizarse a través de la modalidad procesal de despido colectivo, en virtud del artículo 103.3 de esa misma norma ${ }^{45}$.

\subsection{Las consecuencias de la nulidad}

El último aspecto que interesa precisar en relación a la nueva garantía incorporada en el párrafo $2^{\circ}$ del artículo 14.2 del TRLET son los efectos o consecuencias de la nulidad; calificación que, como ya se ha visto, procederá en los casos donde no pueda romperse la presunción legal demostrando que la extinción se fundamenta en la existencia de un problema concreto de falta de capacidad, competencia y/o adaptación de la trabajadora embarazada. Nada se indica al respecto en la norma, ni se introduce ninguna remisión al artículo 55.6 del TRLET, donde podría hallarse la respuesta. Como es bien sabido dicho precepto define los efectos del despido disciplinario nulo estableciendo que el mismo determina "la readmisión inmediata del trabajador con abono de los salarios dejados de percibir". ¿Son también estos los efectos de las extinciones acordadas en período de prueba que deban considerarse nulas en virtud del artículo 14.2.2 ${ }^{\circ}$ del TRLET?

Al final del epígrafe anterior se ha indicado que las impugnaciones de los desistimientos empresariales durante el período de prueba deben canalizarse a través de la modalidad procesal de despido disciplinario, en cuyo bloque normativo figura el artículo 113 de la LJS, que reitera la regla establecida en aquel precepto estatutario. Queda claro pues que la sentencia que declare la nulidad de una extinción contractual en período de prueba en base al artículo 14.2.2 $2^{\circ}$ del TRLET deberá condenar a la readmisión de la trabajadora embarazada y el pago de los salarios de tramitación correspondientes. No cabrá, por el contrario, como acertadamente ha apuntado la doctrina ${ }^{46}$, reconocer una indemnización por los daños y perjuicios eventualmente causados, porque ésta sólo puede acordarse cuando la impugnación se haya planteado a través de la vía de tutela ordinaria, esto es, alegando vulneración del derecho a la no discriminación a través de la modalidad procesal de tutela de derechos fundamentales (artículos 177 y siguientes de la LJS).

La limitación apuntada en el párrafo anterior puede generar situaciones de desprotección cuando la extinción realmente constituya una reacción al estado de embarazo de la trabajadora. Para salvar la situación se ha propuesto la acumulación en la demanda de dos pretensiones ${ }^{47}$. En la primera debería postularse la nulidad por

${ }^{45}$ Dicho precepto establece que deben impugnarse a través de la modalidad procesal de despido disciplinario las decisiones empresariales encaminadas a la extinción del contrato de trabajo que no tengan asignada una modalidad distinta, y entre tales decisiones se incluye sin ninguna duda el desistimiento durante el período de prueba.

${ }^{46}$ Agustí MARAgall, "Igualdad y conciliación...”, p. 39.

${ }^{47}$ La propuesta corresponde también a Agustí MARAgall, "Igualdad y conciliación...", p. 39. En su opinión, "la tutela objetiva y la declaración de nulidad por causa de estar la trabajadora embarazada en 
discriminación y aportar los indicios necesarios para generar la presunción de lesión del derecho fundamental; postulación que en caso de prosperar comportaría la declaración de nulidad y abriría la puerta al reconocimiento de una indemnización en los términos previstos por el artículo 183 de la LJS. La segunda, de carácter subsidiario, reclamaría la nulidad en base al artículo 14.2.2 ${ }^{\circ}$ del TRLET.

\section{Reflexiones finales}

La reforma operada por el RDL 6/2019 supone un importantísimo paso adelante en la protección de las trabajadoras embarazadas frente a la extinción contractual durante el período de prueba y viene a corregir un previo posicionamiento jurisprudencial bastante polémico, que se adoptó con importantes discrepancias internas y suscitó la crítica de la doctrina mayoritaria.

El nuevo párrafo segundo del artículo 14.2 del TRLET extiende al período de prueba la protección reforzada que a través de la denominada "nulidad objetiva y automática" se estableció dos décadas atrás en relación con el despido. Se facilita así la tutela de las trabajadoras embarazadas en esa fase inicial de la relación laboral, no sólo frente a actuaciones discriminatorias, esto es, ante extinciones acordadas como reacción al estado de embarazo, sino también ante resoluciones que sin responder a ese móvil carezcan de base objetiva. Puede afirmarse, por tanto, que en realidad lo que se lleva a cabo es una reconstrucción lógica del período de prueba en relación a la trabajadora embarazada, limitando el desistimiento empresarial a los supuestos donde se alegue y acredite una falta de aptitud y/o adecuación; una reconstrucción que la doctrina ya había reclamado en más de una ocasión con carácter general ${ }^{48}$. Es razonable otorgar a la parte empresarial un margen de maniobra suficiente para determinar la aptitud y/o adecuación del personal recién contratado durante el período de prueba, pero ello no requiere necesariamente que el desistimiento pueda llevarse a cabo sin necesidad de acreditar causa alguna. La norma reformadora se limita a corregir este último "exceso" normativo para proteger a un colectivo singularmente expuesto, como son las trabajadoras embarazadas.

Aunque el RDL 6/2019 constituye un avance importante, la reforma operada por dicha norma presenta dos aspectos negativos que no pueden dejar de señalarse. El primero es

el momento del cese está recogida en el artículo 108.2.b) LJS con carácter imperativo, por lo que incluso en el caso de que la demandante no la postulara (...) la sentencia deberá declarar necesariamente la nulidad en todo caso por ese motivo", dado que "así lo imponen los términos del artículo 108.2 LJS y el mandato normativo que transpone (la prohibición de despido en situación de embarazo ex artículo 10 de la Directiva 92/85/CEE)"

${ }^{48}$ Sirva como ejemplo FERNÁNEZ MÁRQUEZ, El periodo de prueba..., pp. 22 y siguientes. 
que no se aprovechase para incorporar a la norma estatutaria la obligación establecida por el artículo 10.2 de la Directiva 92/85/CEE, una importante garantía de carácter formal que complementa la protección ofrecida por la nulidad objetiva. Aun existiendo un defecto de transposición, cabe entender, en base al principio de interpretación conforme, que la parte empresarial está obligada a comunicar por escrito con especificación de causa motivadora las extinciones adoptadas durante el período de prueba que afecten a trabajadoras embarazadas (también a las que hayan dado a luz o ese hallen en período de lactancia), siempre que se tenga conocimiento de tal estado.

El segundo aspecto negativo son los interrogantes que, a pesar de su indiscutible fuerza, plantea la nueva garantía establecida en el artículo 14.2.2 ${ }^{\circ}$ del TRLET en lo que refiere tanto a la delimitación del colectivo beneficiado como a su alcance objetivo. La pelota se halla de nuevo en el tejado de los órganos judiciales, pero con unas reglas del juego distintas, diseñadas para otorgar una protección reforzada a las trabajadoras embarazadas en una fase contractual donde resultan particularmente vulnerables. Esperemos que aquellos interrogantes se resuelvan teniendo bien presente esta motivación.

\section{Bibliografía}

Agustí MARAgall, J., "Despido colectivo. Un concepto en constante evolución", ponencia presentada en las Jornadas por el Consejo General del Poder Judicial sobre "Doctrina judicial del Tribunal de Justicia de la Unión Europea y del Tribunal Supremo. Discrepancias interpretativas" (CU 19076), celebradas en Madrid los días 10 a 12 de junio de 2019.

Agustí maragall, J., "Igualdad, conciliación y maternidad. Análisis crítico de las principales novedades en el Real decreto-ley 6/2019", ponencia presentada a las XIII Xornadas de Outono sobre "El Modelo Social Europeo", celebradas el 22 y 23 de noviembre de 2019 (en fase de publicación como capítulo del libro colectivo del evento por la editorial Francis Lefevbre).

BAJO GARCÍA, I., "Embarazo y nulidad objetiva de la extinción del contrato durante el período de prueba", Revista General de Derecho del Trabajo y de la Seguridad Social, número 36, 2014.

BALLESTER PASTOR, M. A., "El RDJ 6/2019 para la garantía de la igualdad de trato y de oportunidades entre mujeres y hombres en el empleo y la ocupación: dios y el diablo en la tierra del sol", Temas Laborales, número 146/2019. 
BALLESTER PASTOR, M. A., "El significado de la tutela efectiva contra el despido de la trabajadora embarazada. Lo que dice y lo que quiere decir la STJUE de 22 de febrero de 2018, asunto Porras Guisado", Trabajo y Derecho, número 45, 2018.

CARRASCO DURÁN, M., "La jurisprudencia constitucional sobre discriminación por embarazo en el ámbito de las relaciones laborales", Actualidad Jurídica Aranzadi, número 875, 2013.

FABREgat Monfort, G., "Las novedades en materia de igualdad de género en el mercado de trabajo", Revista General de Derecho del Trabajo y de la Seguridad Social, número 53, 2019.

FERNÁNDEZ MÁRquez, Ó., El periodo de prueba en el contrato de trabajo, Tirant lo Blanch, Valencia, 2014.

Gallego Moya, F., El periodo de prueba en el contrato de trabajo, Aranzadi, Cizur Menor, 2016.

GonZÁlez GonZÁlez, C., "Modificaciones de las condiciones de trabajo y su incidencia en el cómputo de los umbrales del despido colectivo en la doctrina del Tribunal de Justicia de la Unión Europea”, Aranzadi Doctrinal, número 4, 2018.

Lousada Arochena, F., "Prohibición de despido de las trabajadoras embarazadas y período de prueba", Revista de Derecho Social, número 63, 2013.

Pastor Martínez, A., "Las medidas laborales del Real Decreto-Ley 6/2019, de 1 de marzo, de medidas urgentes para garantía de la igualdad de trato y de oportunidades entre mujeres y hombres en el empleo y la ocupación: un paso hacia la efectividad de la igualdad de trato y de oportunidades desde la corresponsabilidad", IUSLabor, número $1 / 2019$.

PÉRez Del PrAdo, D., "La heterogénea tutela antidiscriminatoria de la trabajadora embarazada. La STC 173/2013 y la delimitación de los ámbitos de menor protección”, Información Laboral, número 1, 2014.

RodríGUEZ-PIÑERo RoYo, M., "El período de prueba”, Revista Española de Derecho del Trabajo, número 100, 2000. 
TALÉNS VisCONTI, E., "Extinción del contrato de una trabajadora embarazada durante el período de prueba. Comentario a la STC (Pleno) 173/2013, de 10 de octubre", Revista Bolivariana de Derecho, número 18, 2014.

Val Tena, A. L., Pacto de prueba y contrato de trabajo, Civitas, Madrid, 1998. 